\title{
A method for ultimate strength design of rectangular reinforced concrete beams in combined torsion, bending and shear*
}

\author{
B. Kuyt
}

\section{Contribution by Lennart Elfgren, Tekn dr and Inge Karlsson, Tekn lic \\ Chalmers University of Technology, Division of Concrete Structures}

Since 1968 we have been engaged in a research project on torsion of concrete structures at Chalmers University of Technology ${ }^{(1-5)}$. We have worked with a truss model similar to Ir Kuyt's. However, we have not used quite the same assumptions. As one of the assumptions is of great importance for the outcome of the analysis, we would like to discuss its validity and implications.

In the analysis, Ir Kuyt studies the equilibrium for each side of the beam separately. When the reinforcement yields in one of the sides, the failure moment is supposed to be reached. However, it has been found in tests conducted by, for example, Lampert and Thürlimann ${ }^{(6)}$ that, before the ultimate capacity is attained, yielding has also started in the stirrups in the adjoining sides of the beam. If this fact is considered and if the equilibrium equations at failure are established for the over-all cross-section, it will be found that equation 2 of the paper gives too low a value of the failure moment for pure torsion. Instead it will be found that equation 1 is valid not only for beams with a uniform distribution of the longitudinal bars along the perimeter of the cross-section but also for beams where the longitudinal reinforcement is concentrated in the corners.

The use of a more complete failure criterion as has been outlined above with yielding of the reinforcement in three sides also has consequences for the analysis of beams loaded in combined torsion, bending and shear. Ir Kuyt here simply proposes a linear interaction between torsion and shear. However, if the equilibrium equations of failure are studied for the over-all crosssection, it will here be found that the interaction is governed by three second-degree parabolas ${ }^{(2)}$. Each one of the parabolas can be derived from one of three different modes of failure. These three modes are characterized by that side of the beam in which yielding of the reinforcement starts.

As the shear force, $V$, is proportional to the bending moment, $M$, the interaction for such beams loaded in combined torsion, bending and shear can be presented in two-dimensional diagrams. An example is given in Figure I. The full lines there represent the theoretical interaction curves for loading in torsion and bending, and the broken lines represent the reduction caused by the vertical shear force according to the

*Pages 15 to 24 of Magazine No. 78

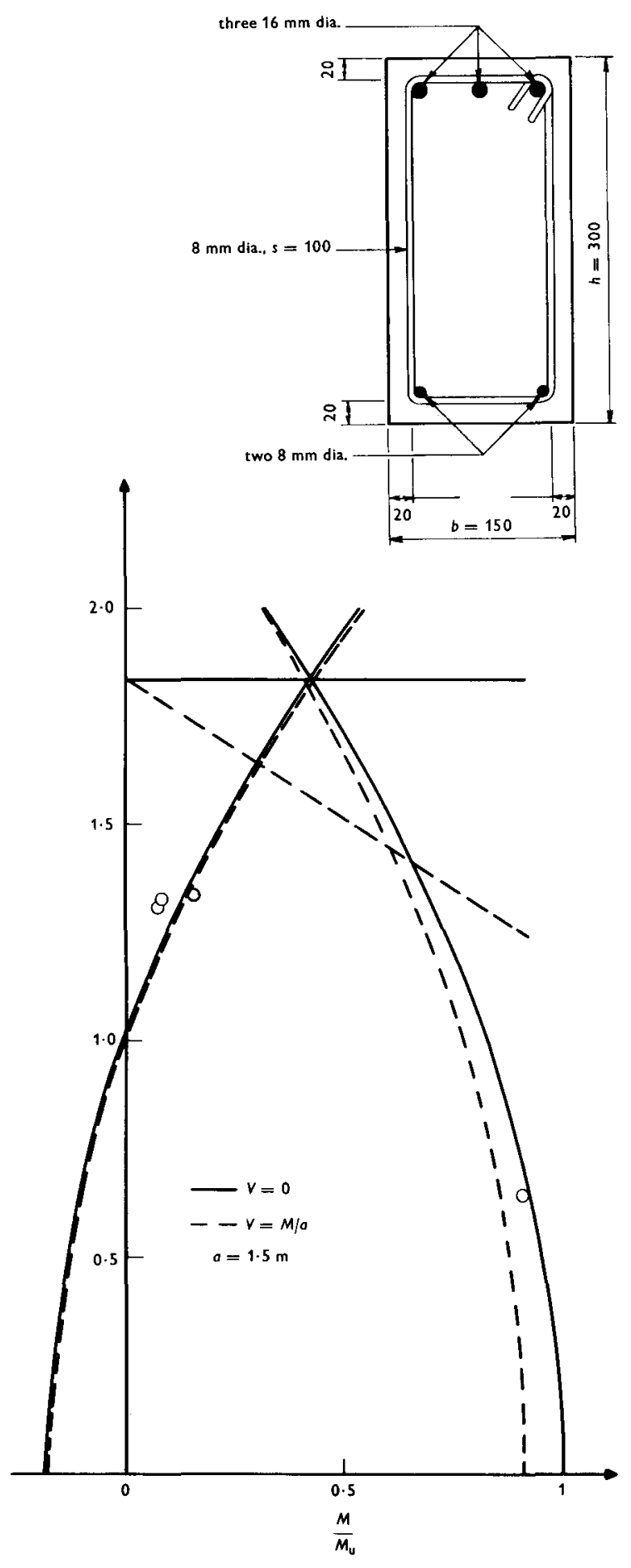

Figure I: Non-dimensional interaction diagram for combined torsion, bending and shear. Method of analysis and test data of the contributors ${ }^{(2,3)} \cdot M_{\mathrm{u}}$ and $T_{\mathrm{u}}$ denote the theoretical failure moments for pure bending and pure torsion respectively. The length of the shear span is denoted a. 
analysis of the writers ${ }^{(2)}$. The circles represent test results ${ }^{(3)}$. As can be seen, the interaction is governed by three curves, all of them being influenced by the presence of the shear force. In Ir Kuyt's interaction diagrams, on the other hand, only two curves were used and only one of these was influenced by the shear force.

\section{Reply by the author}

I thank $\mathrm{Dr}$ Elfgren and $\mathrm{Mr}$ Karlsson for their thoughtful and constructive contribution. As it is now more than eighteen months since the paper was submitted, this seems an appropriate opportunity to consider some issues in more detail than was done in the original paper. As regards the validity of equations 1 and 2, I would like to refer to the discussion about the same point in MCR 81 . The contributors also raise questions regarding the stresses in the stirrups and whether the interaction between shear and torsion is linear or not. Concerning these questions, we must not lose sight of the fact that an important aim of this type of research must be - besides deepening of theoretical knowledge-to develop design methods as simple as possible, giving reliable results, without being unduly conservative.

\section{INFLUENCE OF STIRRUP STRESSES UPON DESIGN EQUATIONS}

With this starting-point in mind, it seems useful to write the design equations for different assumptions regarding the stresses in the stirrups. Assuming that the stirrups at the ultimate stage will yield at three sides of the beam, we find for a beam as shown in Figure 1:

$$
\begin{aligned}
& A_{\mathrm{b} 1} f_{\mathrm{y} 1}=-\frac{M}{z}+\left(\frac{V}{2}+\frac{T y_{1}}{2 A_{\mathrm{cl}}}+\frac{T x_{1}}{2 A_{\mathrm{cl}}(1+\xi)}\right) \psi \ldots \\
& A_{\mathrm{b} 2} f_{\mathrm{y} 1}=+\frac{M}{z}+\left(\frac{V}{2}+\frac{T y_{1}}{2 A_{\mathrm{cl}}}+\frac{T x_{1}}{2 A_{\mathrm{cl}}(1+\xi)}\right) \psi \ldots
\end{aligned}
$$

Assuming that the stirrups will yield at one side of the beam, we find that the equations become:

$$
\begin{aligned}
& A_{\mathrm{b} 1} f_{\mathrm{y} 1}=-\frac{M}{z}+\left(\frac{V}{2}+\frac{T u_{\mathrm{cl}}}{4 A_{\mathrm{cl}}}\right) \psi \ldots \ldots \\
& A_{\mathrm{b} 2} f_{\mathrm{y} 1}=+\frac{M}{z}+\left(\frac{V}{2}+\frac{T u_{\mathrm{cl}}}{4 A_{\mathrm{cl}}}\right) \psi \ldots \ldots
\end{aligned}
$$

Replacing the perimeter of the cross-section $u_{\mathrm{cl}}$ by $4 y_{1}$ - as has been done in the case of four corner barswe finally get:

$$
A_{\mathrm{b} 1} f_{\mathrm{yl}}=-\frac{M}{z}+\left(\frac{V}{2}+\frac{T}{x_{1}}\right) \psi \ldots \ldots \ldots
$$

Finally we would like to say that we have found the simplicity of the approach presented by Ir Kuyt very attractive. The approach also gives conservative results for the load-carrying capacity in pure torsion. However, for combined torsion, bending and shear this is not generally the case. For this reason, the approach ought to be studied further.

$$
A_{\mathrm{b} 2} f_{\mathrm{y} 1}=+\frac{M}{z}+\left(\frac{V}{2}+\frac{T}{x_{1}}\right) \psi \ldots \ldots \ldots
$$

For all assumptions we find the same design equations for the stirrup reinforcement:

$$
\frac{A_{\mathrm{sv}} f_{\mathrm{yv}}}{s_{\mathrm{v}}}=\frac{1}{\psi}\left(\frac{V}{2 z}+\frac{T}{2 A_{\mathrm{cl}}}\right) \approx \frac{1}{\psi} \frac{T(1+\xi)}{2 A_{\mathrm{cl}}} \ldots \ldots
$$

In my opinion, the results of equations $B-D$ and C-D will be on the side of safety, not only in the case of pure torsion but also in the case of combined bending, torsion and shear (as long, of course, as the beam can be considered to be under-reinforced).

It is interesting to note that, in the case of bending and shear only ${ }^{(7)}$, the equations imply that all tensile forces will be resisted by reinforcement; this is in contrast to some Codes, which allow part of the shear force to be resisted by the concrete. This fact also strongly supports my conviction that the equations will give reliable results.

After publication of the paper under discussion, I did realize that the 'shift-rule'* still has to be applied to the design equations given in the paper, which means that the bending moment $M$ must be read as $\left(M+\frac{1}{2} V z \psi\right)$. When this is done, equations 15 and 17 of the original paper become the expressions $\mathrm{C}$ written above. The contributors therefore rightly point out that all design equations, as well as the interaction curves, will be influenced by the shear force.

Since the assumption that the stirrups will yield at three sides of the beam leads to somewhat cumbersome design equations, it will be a matter of personal preference for the designer to decide in what measure the possible theoretical advantage of using equations A compensates for the practical disadvantage.

\section{INTERACTION SURFACE AND INTERACTION CURVES}

Expressions for the interaction surfaces corresponding to the combinations (A-D) and (B-D) respectively can be derived by eliminating the factor $\psi$ from these

*i.e. displacement of the $M$ diagram by a distance $1_{2}^{1} z$ (compare the 1970 CEB Recommendations, R43.145). 
combinations. In this derivation we find as a first result the relations:

$$
\begin{aligned}
& M_{\mathrm{u}}=A_{\mathrm{b} 2} f_{\mathrm{y} 1} z \ldots \ldots \ldots \ldots \ldots
\end{aligned}
$$

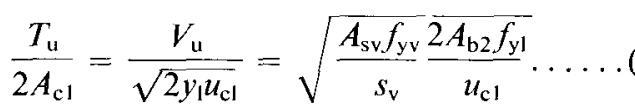

and arrive afterwards at the equation of the interaction surface:

$$
\left(\frac{M}{M_{\mathrm{u}}}\right)+\left(\frac{T}{T_{\mathrm{u}}}\right)^{2}+\left(\frac{V}{V_{\mathrm{u}}}\right)^{2}+\left(\frac{T}{T_{\mathrm{u}}} \frac{V}{V_{\mathrm{u}}}\right) c=1 \ldots
$$

The factor $c$ in equation $\mathrm{F}$ depends upon the shape of the beam and upon the assumptions made regarding the stirrup stresses.

If we assume that the stirrups will yield at one side of the beam, the factor $c$ varies from $2 \cdot 0$ to $2 \cdot 1$; if we assume that the stirrups will yield at three sides of the beam, the factor $c$ varies from $1 \cdot 4$ to $2 \cdot 0$.

The intersections of the interaction surfaces with the plane $V-T$ have been sketched in Figure II; this Figure shows clearly that these intersections (an ellipse and hyperbola respectively) can be very well approximated by a straight line. Therefore, we can write as general expression for the interaction surface (see Figure III) :

$$
\frac{M}{M_{\mathrm{u}}}+\left(\frac{T}{T_{\mathrm{u}}}+\frac{V}{V_{\mathrm{u}}}\right)^{2}=1 \ldots \ldots \ldots
$$

This expression is independent of the shape of the (rectangular under-reinforced) beam and of assumptions concerning the stirrup stresses. The intersections of this surface with planes parallel to the plane $V-T$ have the form (see Figure III):

$$
\left(\frac{T}{T_{\mathrm{u}}}+\frac{V}{V_{\mathrm{u}}}\right)=\sqrt{1-\frac{\bar{M}}{M_{\mathrm{u}}} \ldots \ldots \ldots}
$$

so it can be concluded that-with very good approximation-indeed can be spoken of a linear interaction between torsion and shear.

\section{FINAL OBSERVATIONS}

Not being conversant with the research work of Mr Karlsson and Dr Elfgren on combined bending, shear and torsion, I find it difficult to comment on some of their statements. As discussed in the foregoing, for the beam shapes that are normally used in practice, the question whether the stirrups will yield at three sides of the beam or at one side is of only minor importance for the shape of the interaction surface. Examination of Figure I leads me to suppose that the main difference between the two methods will lie in the number of supposed failure modes; in other words, do we need three modes of failure, as proposed by the contributors or can we make do with two modes of failure, as suggested in the original paper?

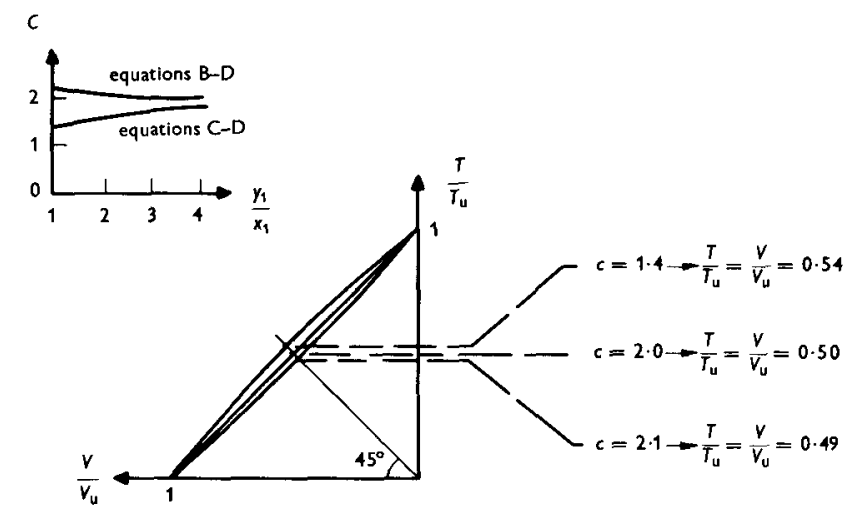

Figure II: Intersections of interaction surfaces (corresponding to different values of $c$ ) with the plane $V-T$.

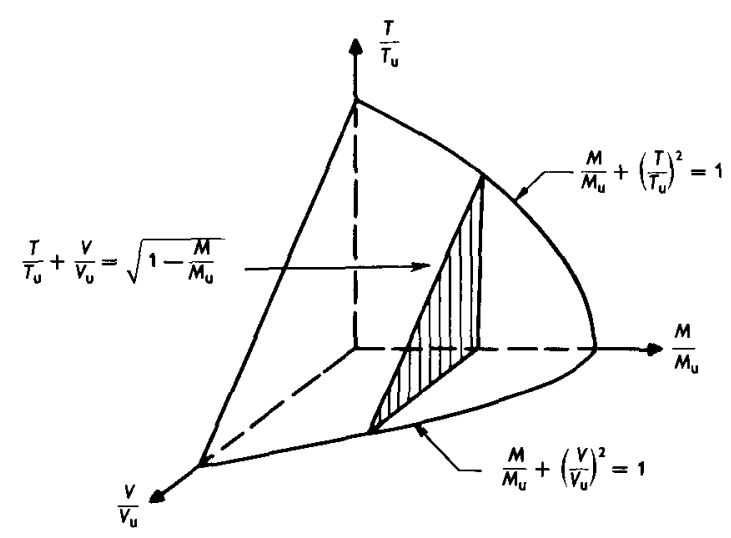

Figure III: Non-dimensional interaction surface for rectangular beants with a symmetrical arrangement of the longitudinal bars.

The physical background of the design equations given is provided by the assumption that redistribution of forces between longitudinal reinforcement and stirrups is possible, so that for under-reinforced beams both stirrups and longitudinal bars will yield at failure. Therefore, when the longitudinal reinforcement consists of top bars, $A_{b 1}$, and bottom bars, $A_{b 2}-$ which is the case in Figure $\mathrm{I}$ - there are two obvious modes of failure:

(a) yielding of stirrups and bottom bars;

(b) yielding of stirrups and top bars

Particularly in the case of beams as shown in Figure $I$, there is no great argument in favour of a third mode of failure. It is a pity that the test results presented (Figure I) do not fall into the range of the proposed third mode of failure; therefore more experimental data will be needed to clear up this issue.

If this reply is to be kept within limits, it is not possible to dwell at length upon the general case with longitudinal bars at all sides of the beam. Therefore it may just be noted that, for an arrangement of the longitudinal bars as indicated in Figure IV, it can be 

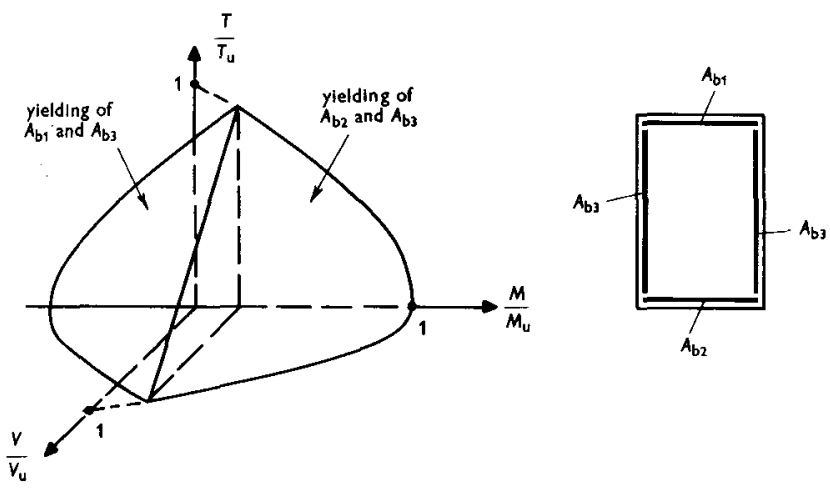

Failure moment for pure bending:

$$
M_{\mathrm{u}}=\left(A_{\mathrm{b} 2}+A_{\mathrm{b} 3}\right) z f_{\mathrm{y} 1}
$$

Failure moment for pure torsion:

$$
\frac{T_{\mathrm{u}}}{2 A_{\mathrm{cl}}}=\sqrt{\frac{A_{\mathrm{sv}} f_{\mathrm{yv}}}{s_{\mathrm{v}}} \frac{2\left(A_{\mathrm{b} 2}+A_{\mathrm{b} 3}\right) f_{\mathrm{y} 1}}{u_{\mathrm{cl}}}}
$$

Failure moment for 'pure shear loading':

$$
V_{\mathrm{u}}=\frac{\sqrt{2 y_{1} u_{\mathrm{cl}}}}{2 A_{\mathrm{cl}}} T_{\mathrm{u}}
$$

Figure IV: Non-dimensional interaction surface for rectangular beams with non-symmetrical arrangement of the longitudinal bars.

shown that equation $(G)$ retains its validity as equation of the interaction surface. A possible set of design equations applicable to the case shown in Figure IV (stirrups yielding at one side of the beam) is as follows:

$$
A_{\mathrm{b} 1} f_{\mathrm{yl}}=-\frac{M}{z}+\left(\frac{V}{2}+\frac{T}{2 y_{1}}\right) \psi
$$

\section{REFERENCES}

1. ELFGREN, L. and KARLSSON, I. Vridning av betongkonstruktioner. En litteraturöversikt. (Torsion of structural concrete. A state of the art review.) Göteborg, Chalmers University of Technology, Division of Concrete Structures, December 1969. pp. 179. Report 69:2.

2. ELFGREN, L. Reinforced concrete beams loaded in combined torsion, bending and shear. A study of the uttimate loadcarrying capacity. Göteborg, Chalmers University of Technology, Division of Concrete Structures, November 1971. pp. 201. Publication 71:3.

3. ELFGREN, L. and KARLSSON, I. Tests on rectangular reinforced concrete beams in combined bending, torsion and shear. Göteborg, Chalmers University of Technology, Division of Concrete Structures, November 1971. pp. 128. Report $71: 2$.

4. KARLSSON, I. Torsional stiffness of reinforced concrete structures in pure torsion. Göteborg, Chalmers University of Technology, Division of Concrete Structures, March 1971. pp. 102. Report $71: 1$

$$
\begin{aligned}
& A_{\mathrm{b} 2} f_{\mathrm{y} 1}=+\frac{M}{z}+\left(\frac{V}{2}+\frac{T}{2 y_{1}}\right) \downarrow \\
& A_{\mathrm{b} 33} f_{\mathrm{y} 1}=\left(\frac{T}{2 x_{1}}\right) \psi \\
& \frac{A_{\mathrm{sv}} f_{\mathrm{yv}}}{S_{\mathrm{v}}}=\frac{1}{z}\left(\frac{V}{2}+\frac{T}{2 x_{1}}\right) \frac{1}{\psi}
\end{aligned}
$$

Finally, it may be pointed out that equations, similar to those discussed here for beams loaded in bending, torsion and shear, have already been proposed (and applied) for the calculation of orthogonal mesh reinforcement in slabs (or shells), when the directions of the mesh deviate from those of the principal moments (or forces). ${ }^{(8,9)}$

For a shell element subjected to a normal force $N_{\mathrm{x}}$, a normal force $N_{\mathrm{y}}$ and a shear force $N_{\mathrm{xy}}$, the equations can be written:

$$
\begin{aligned}
& A_{\mathrm{x}} f_{\mathrm{yx}}=N_{\mathrm{x}}+\psi\left|N_{\mathrm{xy}}\right| \\
& A_{\mathrm{y}} f_{\mathrm{yy}}=N_{\mathrm{y}}+\frac{1}{\psi}\left|N_{\mathrm{xy}}\right|
\end{aligned}
$$

in which $A_{\mathrm{x}}$ and $A_{\mathrm{y}}$ represent the reinforcements per unit length of shell.

These equations can be derived in several ways: by resolving a plane stress field into three linear stress fields ${ }^{(8)}$; by making use of truss analogy ${ }^{(8)}$; or from a normal moment criterion ${ }^{(9)}$. For a beam loaded in bending, torsion and shear, design equations can be found by applying equations $(\mathrm{J})$ to each side of the beam, taking into account that the coefficient $\psi$ need not have the same value for each side of the beam.

5. KARLSSON, I. and FLFGREN, L. Torsional stiffness of reinforced concrete members subjected to pure torsion. Magazine of Concrete Research. Vol. 24, No. 80. September 1972. pp. $149-156$.

6. LAMPERT, P. and THÜRLIMANN, B. Torsions-Biege-Versuche an Stahlbetonbalken. (Reinforced concrete beams under combined torsion and bending.) Zürich, Swiss Federal Institute of Technology, Institute of Structural Engineering, January 1969. pp. 116. Research Report No. 6503-3.

7. KUYT, B. Over de dwarskrachtsterkte van slanke balken met verticals beugels. (Shear strength of slender beams with vertical stirrups.) Cement. Vol. 24. No.6. June 1972. pp. 243-251. No. 9. September 1972. pp. 346-353.

8. KUYT, B. Zur Frage der Netzbewehrung von Flächentragwerken. (Calculation of mesh reinforcement-orthogonal or skew - in plates and shells.) Beton- und Stahlbetonbau. Vol. 59, No. 7. July 1964. pp. 158-163.

9. WOOD, R. H. The reinforcement of slabs in accordance with a predetermined field of moments. Concrete. Vol. 2, No. 2. February 1968. pp. 69-76. 